\title{
The prevalence of diabetes in Afghanistan: a systematic review and meta-analysis
}

\author{
Sohail Akhtar ${ }^{1 *}$ D, Jamal Abdul Nasir ${ }^{1}$, Amara Javed ${ }^{1,2}$, Mariyam Saleem¹, Sundas Sajjad ${ }^{1}$, Momna Khan ${ }^{1}$, \\ Abdul Wadood ${ }^{3}$ and Khwaja Saeed ${ }^{4}$
}

\begin{abstract}
Background: The aim of this paper is to investigate the prevalence of diabetes and its associated risk factors in Afghanistan through a systematic review and meta-analysis.

Methods: A comprehensive literature search was conducted using EMBASE, PubMed, Web of Sciences, Google Scholar and the Cochrane library, carried out from inception to April 312,020, without language restriction. Metaanalysis was performed using DerSimonian and Laird random-effects models with inverse variance weighting. The existence of publication bias was initially assessed by visual inspection of a funnel plot and then tested by the Egger regression test. Subgroup analyses and meta-regression were used to explore potential sources of heterogeneity. This systematic review was reported by following the PRISMA guidelines and the methodological quality of each included study was evaluated using the STROBE guidelines.
\end{abstract}

Results: Out of 64 potentially relevant studies, only 06 studies fulfilled the inclusion criteria and were considered for meta-analysis. The pooled prevalence of diabetes in the general population based on population-based studies were 12.13\% (95\% Cl: 8.86-16.24\%), based on a pooled sample of 7071 individuals. Results of univariate metaregression analysis revealed that the prevalence of diabetes increased with mean age, hypertension and obesity. There was no significant association between sex (male vs female), smoking, the methodological quality of included articles or education (illiterate vs literate) and the prevalence of diabetes.

Conclusions: This meta-analysis reports the 12.13\% prevalence of diabetes in Afghanistan,with the highest prevalence in Kandahar and the lowest in Balkh province. The main risk factors include increasing age, obesity and hypertension. Community-based care and preventive training programmes are recommended.

Trial registration: This review was registered on PROSPERO (registration number CRD42020172624).

Keywords: Prevalence, Diabetes, Afghanistan, Meta-analysis and systematic review

\section{Background}

Diabetes is a major public health problem and its frequency is drastically increasing all over the world [1]. The prevalence of type- 2 diabetes is rising worldwide as a result of ageing of the population [2], rising levels of overweight and obesity in youth and young adults [3], increasing levels of physical inactivity and poor diet [4].

\footnotetext{
* Correspondence: s.akhtar@gcu.edu.pk; akhtar013@gmail.com

'Department of Statistics, Government College University, Lahore, Pakistan Full list of author information is available at the end of the article
}

Globally, it is projected that the diabetes prevalence will increase from 451 million people in the year 2017 to 693 million people by the end of 2045 [5], with $79 \%$ of all diabetes cases occurring in low and middle income countries [6]. Worldwide, diabetes prevalence was estimated to be $9 \%$ in 2014 among the adult population older than 18 years [1]. It was also reported that $49.7 \%$ of individuals living with diabetes are still undiagnosed [7]. The life expectancy of individuals with type-2 diabetes is reduced by approximately 10 years compared

(c) The Author(s). 2021 Open Access This article is licensed under a Creative Commons Attribution 4.0 International License, which permits use, sharing, adaptation, distribution and reproduction in any medium or format, as long as you give appropriate credit to the original author(s) and the source, provide a link to the Creative Commons licence, and indicate if changes were made. The images or other third party material in this article are included in the article's Creative Commons licence, unless indicated otherwise in a credit line to the material. If material is not included in the article's Creative Commons licence and your intended use is not permitted by statutory regulation or exceeds the permitted use, you will need to obtain permission directly from the copyright holder. To view a copy of this licence, visit http://creativecommons.org/licenses/by/4.0/. The Creative Commons Public Domain Dedication waiver (http://creativecommons.org/publicdomain/zero/1.0/) applies to the data made available in this article, unless otherwise stated in a credit line to the data. 
with those without the condition, and $80 \%$ of type- 2 diabetes patients die from cardiovascular complications [7]. More than $60 \%$ of the world diabetic population reside in Asian countries, and Asians are more likely to develop diabetes at earlier ages, and with a lower body mass index, than Europeans [8].

Afghanistan is one of the Asian developing countries and facing a growth in the prevalence of diabetes. According to the World Diabetes Foundation estimates, around 1 million people are living with diabetes in Afghanistan and between one and 2 million diabetes cases are undiagnosed [9]. According to the human development index of the United Nations, Afghanistan stands at 168th position out of 189 countries and territories [10]. With limited health care facilities for diabetics, Afghanistan is ill-equipped to cope with this epidemic. Unfortunately, there has been no official nationwide survey to estimate the prevalence of diabetes in Afghanistan. However, a few research studies have been published which report the prevalence of diabetes and its risk factors in different regions of the country. This prevalence in the general population varies among the published studies. The main purpose of this systematic review and meta-analysis is to identify, summarize and estimate the pooled prevalence of diabetes in Afghanistan based on published studies. In addition, we also investigate the associated risk factors of diabetes.

To the best of our knowledge, this is the first systematic review and meta-analysis to estimate the pooled prevalence of diabetes in Afghanistan.

\section{Methods}

\section{Design}

The results were defined using the Preferred Reporting Items for Systematic and Meta-analyses (PRISMA) guidelines [11]. The PRISMA 2009 checklist is attached in supplementary file S1. The protocol of this study was registered with the International Prospective Register of Systematic Reviews (PROSPERO), with protocol registration number CRD42020172624.

\section{Literature search}

A comprehensive literature search was conducted to identify potential articles published on the prevalence of diabetes in Afghanistan. The search was carried out systematically using the following electronic websites: PubMed, Medline, EMBASE, Google Scholar and the Cochrane Library. We considered studies published from inception to April 2020. Using MeSH headings, the terms "Type-2 diabetes", “Type-II diabetes", “T2D”, "prevalence", "Impaired glucose tolerance (IGT)", "risk factors", "risk factor", "glucose intolerance", "glucose abnormalities", "non-communicable diseases", "Afghanistan", and "Afghan" as well as variations thereof were searched for.
Additionally, articles were also searched from reference lists in previously included studies.

\section{Inclusion and exclusion criteria}

The criteria for studies to be included were as follows: (i) articles were published in peer-reviewed journals and reported the prevalence of diabetes; (ii) articles reported population-based or community-based surveys; (iii) articles were published in either English or Pashto.

The criteria used to exclude studies were: (i) irrelevant to diabetes; (ii) not providing clear data; (iii) review articles, case series, or case reports; (vi) relating to the Afghan community living outside of Afghanistan; (v) Articles reported duplicated data (for data published in more than one article) the more up-to-date version was considered and the other articles excluded.

\section{Data extraction}

After selecting the relevant articles, two investigators independently screened the titles and abstracts to consider articles for full text review. The investigators then extracted all the necessary data using a standardized data extraction format in Microsoft Office Excel 2013. Any disagreement between the two investigators was resolved by the third investigator whose decision was regarded as final. The extracted information was: first author surname, year of publication, sex ratio (male/female), age, sample size, the prevalence rate of diabetes, the prevalence of smoking, sampling method, study design and the province in which the study was performed. An extract of these collected data is presented in Table 1, using the Preferred Reporting Items for Systematic and Meta-analyses (PRISMA) guidelines [11].

\section{Methodological quality of included studies}

Two authors independently assessed the methodological quality of each of included studies by using Strengthening the Reporting of Observational Studies in Epidemiology (STROBE) guidelines [18]. We categorized the quality of each included study as Good (G) if it scored at least 70\% of the points, Fair (F) if it scored $50-69 \%$ of the points, and Poor $(\mathrm{P})$ if its points score was less than $50 \%$.

\section{Statistical analysis}

Meta-analysis was performed using the statistical software R version. 3.6.1 [19]. for Microsoft Windows, using two packages ("meta" and "metafor"). Random effects meta-analysis models were used to investigate the pooled prevalence of diabetes using DerSimonian and Laird's approach with 95\% confidence intervals (CIs) [20]. The inverse of the Freeman-Tukey double arcsine transformation was used to stabilize the variance of each study [21]. A forest plot was used to assess visually the prevalence estimates and corresponding 95\% confidence 


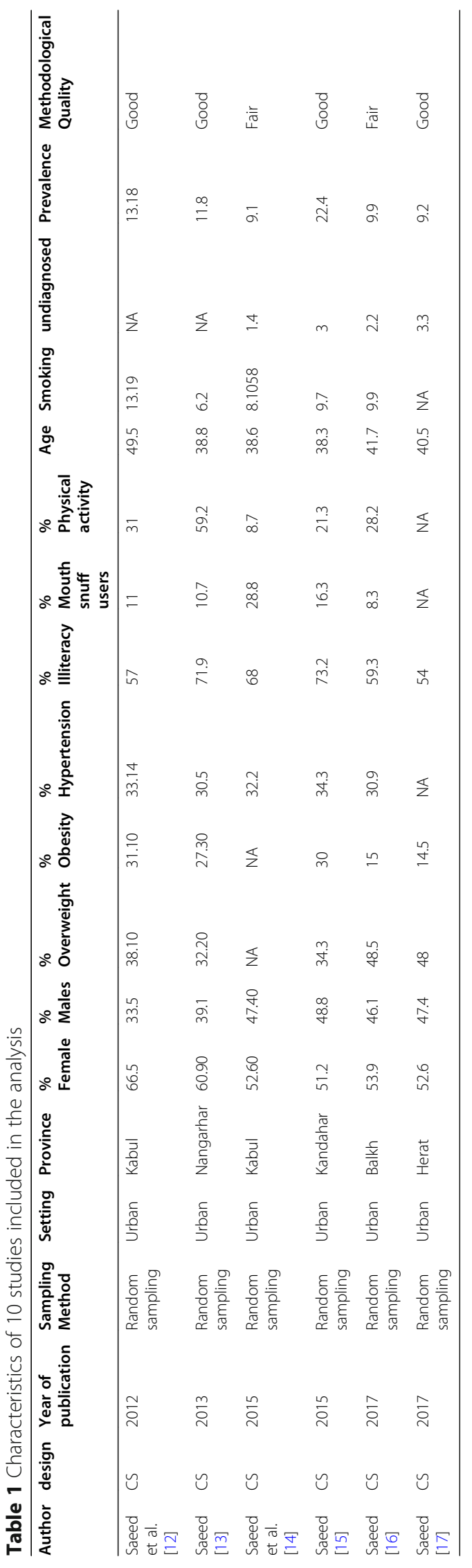


intervals (CIs) across included studies. For the evaluation of statistical heterogeneity across studies, the $I^{2}$-statistic was used [22]. Heterogeneity was considered as high, moderate, low with $I^{2}$ values of 75,50 and $25 \%$ respectively. To identify potential sources of heterogeneity, meta-regression and subgroup analyses were conducted by age, year of publication, hypertension, sex, province, literacy rate, obesity and the methodological quality of the included studies. Publication bias was initially assessed by visual inspection of the funnel plot and then tested by the Egger regression test [23, 24].

\section{Results}

\section{Literature search}

Initially, a total of 64 potential articles was retrieved. Out of these, 36 duplicate articles were removed. After careful review of the titles and abstracts, 12 articles were found irrelevant and then excluded from the process. As the result, only 16 studies were considered for full text reading. Later, 10 studies were excluded after full text reading because they provided no quantitative measure of the prevalence diabetes; overlapped data set; or they were not based in Afghanistan. In the end, only 06 studies were met the inclusion criteria and data were extracted accordingly for the analysis. The flow chart of study selection process is presented in Fig. 1, using the PRISMA flow diagram [11].

\section{Characteristics of the included studies}

The main characteristics of selected studies are summarized in Table 1 [12-17]. All studies used cross-sectional designs and a random sampling procedure. The included studies were published between 2012 and 2017 while the period to which the data relate was from December 2011 to November 2015. The number of subjects per study ranged from 1129 to 1231 , for a total of 7071 subjects across studies. Six studies reported the prevalence of diabetes as an outcome of interest. The existence of diabetes was tested with biological measures in all studies. Considering cut-point definitions of diabetes, all studies used a fasting glucose level of $126 \mathrm{mg} / \mathrm{dL}$. Data were collected from five provinces of Afghanistan. Two studies were conducted in Kabul province [12, 14], one study each in Nangarhar province [13], Kandahar [15], Herat [16], and Balkh [17] provinces. The female proportion varied from $51.2 \%$ [14] to $66.50 \%$ [12]. The average age of participants varied from 38.3 to 49.5 years. The percentage with hypertension ranged from 30.5\%

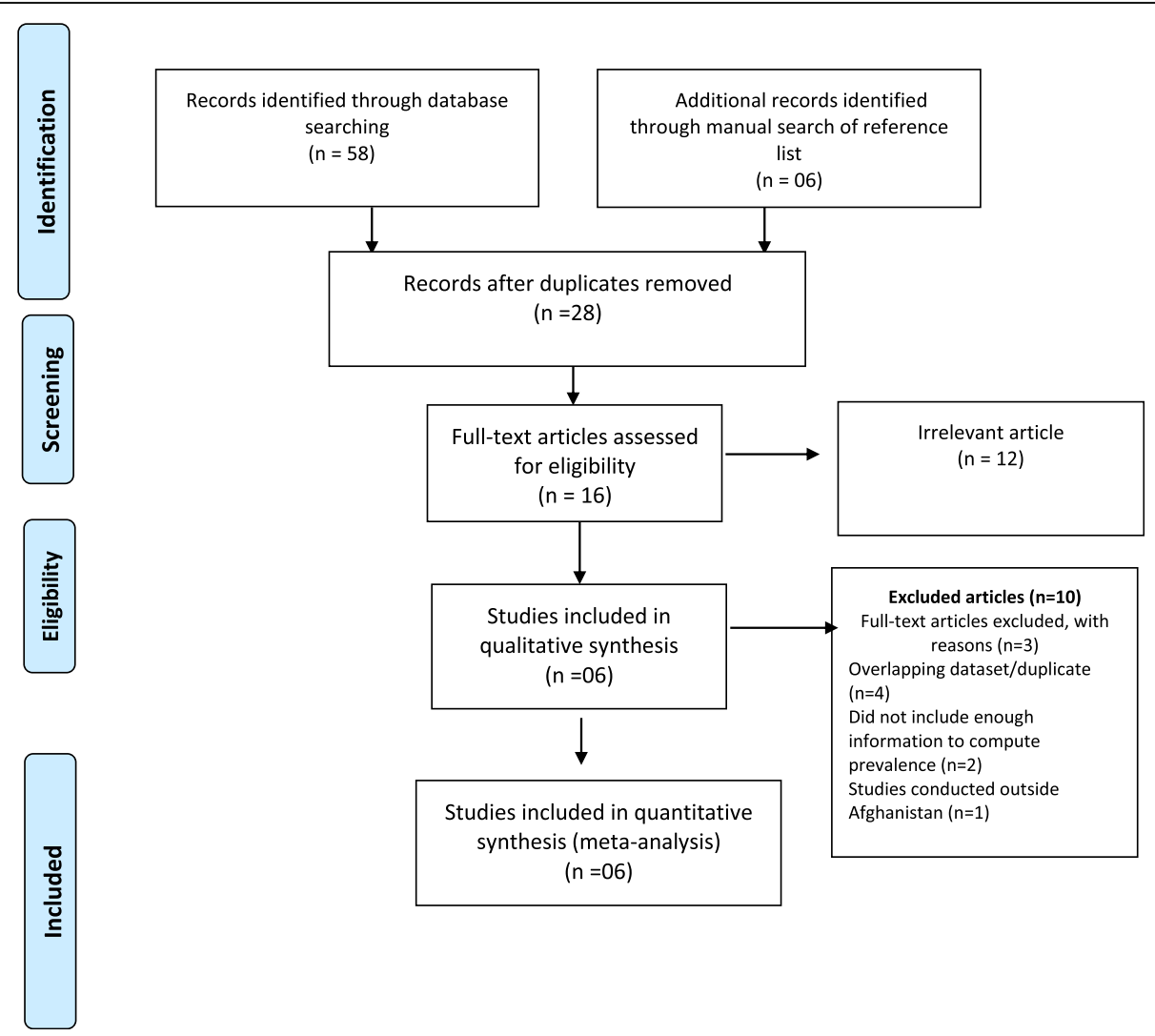

Fig. 1 Flow diagram explaining the number of included and excluded articles in the meta-analysis on diabetes in Afghanistan, considered from the PRISMA 2009 guideline [11] 
[13] to $33.14 \%$ [12], based on five studies. The percentage of obese people varied from $15 \%$ [16] to $30.1 \%$ [12] (six studies). The percentage of illiterate people ranged from 54 to $73.2 \%$ (6 studies). The percentage of smokers ranged from 5.1 to $13.7 \%$. The percentage of overweight people ranged from 32.2 to $48.5 \%$ (five studies).

\section{Pooled meta-analysis}

Statistical analysis of the prevalence of diabetes is described in Table 2. The pooled prevalence of diabetes was $12.13 \%$ (95\% CI: $8.86-16.24 \%, I^{2}=99.3 \%$, based on 06 studies) in a total sample of 7071 individuals. The forest plot of the prevalence estimates and their respective $95 \%$ confidence intervals (CIs) is presented in Fig. 2. The funnel plot (Fig. 3) showed almost no publication bias which is confirmed by the Egger regression test $(p=0.732)$. Furthermore, the no publication bias was confirmed by 'Trim and Fill' sensitivity analysis-as we did not find any hypothetical missing study. The prevalence of undiagnosed diabetes was 9.70\% (95\% CI: 4.99$15.74, I^{2}=97.5 \%$, based on four studies) with a total sample size of 4697 participants.

\section{Heterogeneity and subgroup analysis}

The pooled prevalence among females was $12.56 \%$ (95\% CI: 8.48-17.29), while for males, it was $12.0 \%$ (95\% CI: $8.98-15.55)$. When stratified by age, the pooled prevalence in age groups $25-34$ years, 35-44 years, 45-54 years and 55 years and over was $8.45 \%$ (95\% CI: $3.65-14.97), 13.02 \%$ (95\% CI: 7.54-19.70), $17.12 \%$ (95\% CI: 9.42-26.51), and 19.23\% (95\% CI: 16.20-22.44), respectively. The pooled prevalence in the 55 years and over age group was the highest of the four age groups, which shows that the prevalence of diabetes increases with age (Table 2).

When stratified by province, the prevalence of diabetes was highest $(22.40 \%)$ in Kandahar, compared with 11.08\% (95\% CI: 7.42-15.36) in Kabul, $11.80 \%$ in Nangahar, 9.92\% in Herat, and 9.18\% in Balkh. The difference in the pooled prevalence of diabetes between males and females was insignificant. There was no significant publication bias in all subgroup analyses.

The result of the univariate meta-regression analysis showed that the prevalence of diabetes increased with a mean age $(\beta=0.0107,95 \%$ CI: $0.0002-0.0208, p=0.0343$, $\left.R^{2}=42.34 \%\right)$, hypertension $(\beta=0.0377$, 95\% CI: $0.0034-$ $\left.0.0720, p=0.0311, R^{2}=48.94 \%\right)$ and obesity $(\beta=0.0064,95 \%$ CI: $\left.-0.0007-0.0135, p=0.070, R^{2}=35.64 \%\right)$. The univariate meta-regression analysis also revealed that there was no significant difference by sex (male vs female), sample size, year of publication, smoking, education (illiterate versus literate) or the methodological quality of included studies.

\section{Discussion}

The purpose of this systematic review was to compile all available data reporting the prevalence of diabetes and related risk factors among the adult population of Afghanistan between 2000 and 2019. The information provided in this systematic review and meta-analysis may contribute to improve public health interventions in the country and therefore contribute to reduce the incidence of diabetes. The results showed that the pooled prevalence of diabetes based on 6 population-based

Table 2 Prevalence of diabetes and its risk factors in the adult population of Afghanistan

\begin{tabular}{|c|c|c|c|c|c|c|c|}
\hline Characteristic & Studies & Sample & Cases & $\begin{array}{l}\text { Prevalence, } \\
\%(95 \% \mathrm{Cl})\end{array}$ & $\mathrm{I}^{2}, \%$ & Heterogeneity & P-Egger test \\
\hline Diabetes & 6 & 7071 & 889 & $12.31(8.86-16.24)$ & 0.957 & $<0.001$ & 0.5764 \\
\hline Undiagnosed & 4 & 4697 & 478 & $9.70(4.99-15.74)$ & 0.975 & $<0.001$ & 0.1267 \\
\hline By Sex & & & & & & & 0.0278 \\
\hline Male & 6 & 3976 & 379 & 12.07 (8.98-15.55) & 0.877 & $<0.0001$ & \\
\hline Female & 6 & 3095 & 508 & $12.56(8.48-17.29)$ & 0.945 & $<0.0001$ & \\
\hline \multicolumn{8}{|l|}{ By Age } \\
\hline $25-34$ & 4 & 1922 & 179 & $8.45(3.65-14.97)$ & 0.952 & $<0.0001$ & 0.0359 \\
\hline $35-44$ & 4 & 1179 & 164 & $13.02(7.54-19.70)$ & 0.902 & $<0.001$ & \\
\hline $45-54$ & 4 & 800 & 140 & $17.12(9.42-26.51)$ & 0.907 & $<0.001$ & \\
\hline $55+$ & 4 & 679 & 131 & $19.23(16.20-22.44)$ & 0.078 & 0.354 & \\
\hline By Province & & & & & & & 0.1263 \\
\hline Kabul & 2 & 2355 & 263 & $11.08(7.42-15.36)$ & 0.50 & $<0.001$ & \\
\hline Nangarhar & 1 & 1200 & 536 & 11.8 & - & - & \\
\hline Balkh & 1 & 1231 & 113 & 9.18 & - & - & \\
\hline Herat & 1 & 1129 & 112 & 9.92 & - & - & \\
\hline Kandahar & 1 & 1165 & 261 & 22.40 & - & - & \\
\hline
\end{tabular}




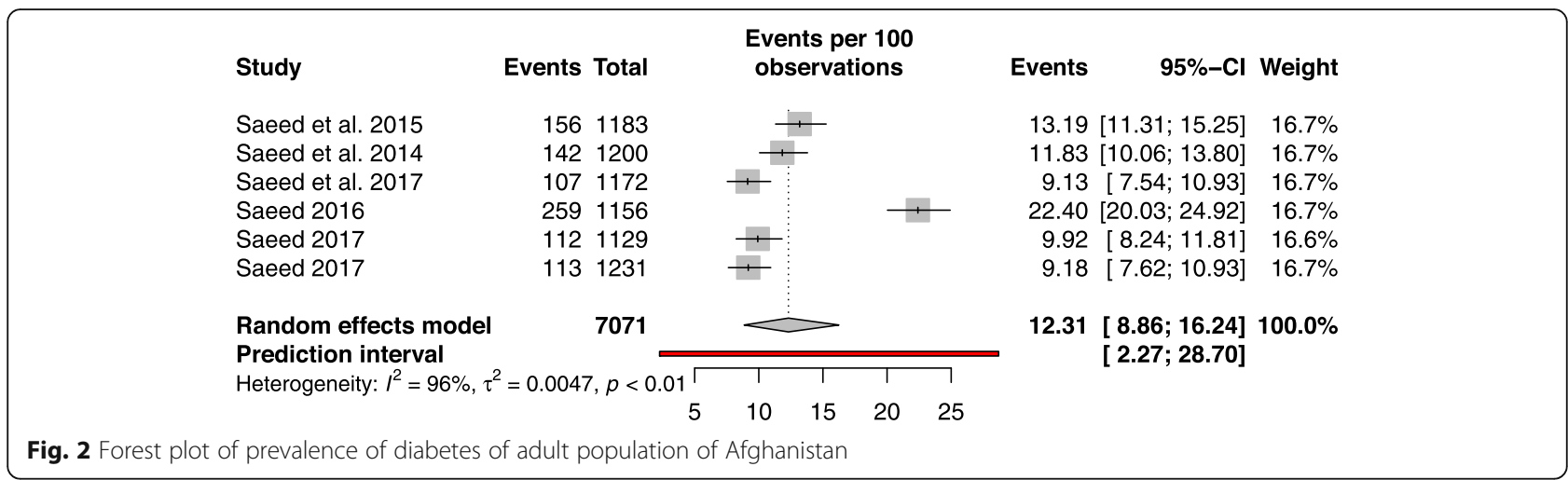

cross-sectional studies was $12.13 \%$, with a total sample of 7071 individuals. Compared with neighbouring countries sharing a similar lifestyle and culture, the pooled prevalence of diabetes in Afghanistan is higher than in Bangladesh (7.8\%) [25] and Nepal (8.4\%) [26], while lower than in Pakistan (14.7\%) [27].

Pashto is one of the official spoken languages in Afghanistan [28] and the Pukhtoon community living both sides of the border of Afghanistan and Pakistan. Pashto is a language which is spoken in southern and eastern region of Afghanistan in which two studies have been conducted including Kandahar and Nangarhar. Those who speak Pashto are Pukhtoons ethnicity which is comparable with Pukhtoons in Pakistan. A population- based survey was performed to explore the prevalence of type-2 diabetes in the Pashto-speaking district of Lower Dir [29] and district Swat [30] (Khyber
Pukhtoonkhuwa, a province of Pakistan). The prevalence of type-2 diabetes in Lower Dir was $11.1 \%$, close to the average prevalence in Afghanistan found in the present analysis.

By comparing age groups, the prevalence of diabetes in $25-34$ year age group was lowest $(8.45 \%)$ while the highest prevalence was found in the age group 55 years and above (19.23\%). People aged 55 years and over are more than twice more likely to have type- 2 than those aged 25-34 years.

By stratifying regionally, the subgroup analysis showed that the prevalence of diabetes in Nangarhar $(11.80 \%)$ and Kabul $(11.08 \%)$ provinces was similar, and also very similar to the nearby Pakistani province of Lower Dir. Diabetes is affecting the whole of Afghanistan with the highest prevalence seen in the Kandahar province (22\%) and the lowest in Balkh province (9.12\%). The big

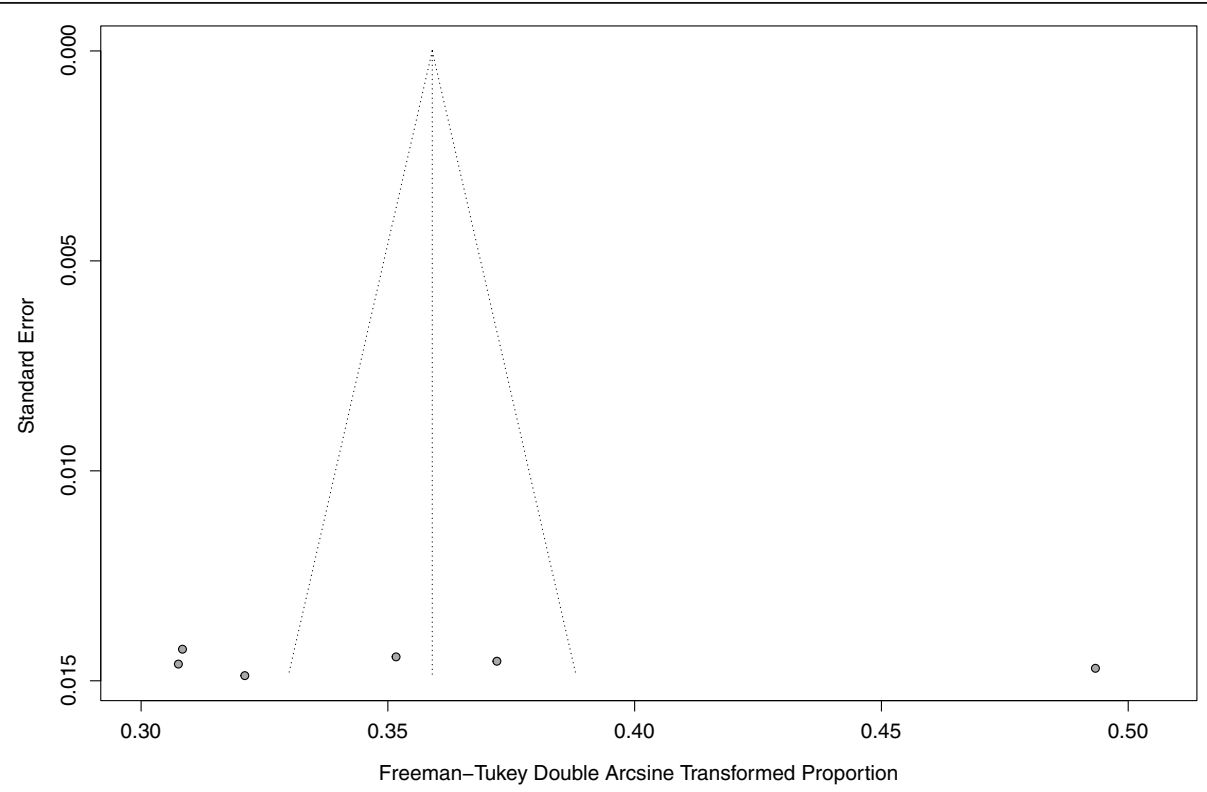

Fig. 3 Funnel plot of the prevalence of diabetes in Afghanistan 
difference of Kandahar compare to other provinces has not been clear. It could be due to genetics, diet or lifestyle. The cross section studies generate hypothesis for testing.

This study has several strengths as well as some limitations. To the best of our knowledge, it is the first systematic review and meta-analysis to estimate the pooled prevalence of diabetes in Afghanistan. We used a rigorous search strategy to explore eligible articles and tried to increase the comparability and quality of included articles by using robust eligibility criteria. No publication bias was found in our analysis which suggests that we did not miss any potential articles that could change the findings of this meta-analysis. The methodological quality of all included articles had a low risk bias (seven were of Good quality and three of Fair quality).

This systematic review and meta-analysis has some limitations. As expected, the meta-analyses revealed high heterogeneity in the estimated pooled prevalence. However, to deal with the problem of high heterogeneity, subgroup analyses and meta-regression were used by adding covariates to the univariate model. Due to high heterogeneity, the results of this meta-analysis should be interpreted with caution.

Another limitation of this review is that type- 1 and type-2 diabetes could not distinguishable in the selected articles. Therefore, we assumed that all reported cases of diabetes were type-2, because it accounts for 90 to $95 \%$ of all diabetes cases [31].

Furthermore, this meta-analysis is based on a limited number of articles (only 6) as well as only 5 out of the 34 provinces of Afghanistan. Due to the limited number of studies in this review, only univariate meta-regression analysis is used to test the significance of each covariate instead of a multivariable meta-regression model.

\section{Conclusions}

The results of this systematic review and meta-analysis suggest that diabetes prevalence in Afghanistan is around $12 \%$, similar to that in neighbouring populations with similar culture and lifestyle. There are variations within the country by province and age, with those aged over 55 years having more than double the prevalence of those aged 25-34 years. There is no significant difference between males and females. Information about the prevalence of diabetes in Afghanistan is limited to 5 of the 34 provinces. Hence, more data are required about other parts of the country, with community-based diabetes testing strategies recommended to diagnose all individuals living with diabetes.

\section{Abbreviations}

Cl: 95\% confidence interval; mg/dL: milligrams per deciliter; PRIS MA: Preferred Reporting Items for Systematic Reviews and Meta-Analyses

\section{Supplementary Information}

The online version contains supplementary material available at https://doi. org/10.1186/s12889-021-10993-5.

\section{Additional file 1.}

Acknowledgements

Thanks Dr. Andy Hinde for the initial comments on the paper and for editing the final draft

\section{Authors' contributions}

SA, JAN, AJ, SS, AW and MK conceived, designed the review and did the data collection analysis for the study. The manuscript was drafted by SA, JAN and MS. KS reviewed the manuscript originally submitted and revised it following the reviewer's comments. SA and KS checked the final analysis and revised the manuscript. The authors read and approved the final manuscript.

Funding

No funding was received for this study.

Availability of data and materials

All relevant data is included within the manuscript file.

\section{Declarations}

Ethics approval and consent to participate

Not applicable here, as this is systematic review and meta-analysis.

Consent for publication

Not applicable.

Competing interests

The authors declare that they have no competing interests.

\section{Author details}

${ }^{1}$ Department of Statistics, Government College University, Lahore, Pakistan. ${ }^{2}$ School of Statistics, Minhaj University, Lahore, Pakistan. ${ }^{3}$ Department of Medical Biotechnology, Edinburgh Napier University, Edinburgh, UK.

${ }^{4}$ Ministry of Public Health, Afghanistan National Public Health Institute (ANPH

I), Kabul, Afghanistan.

Received: 14 May 2020 Accepted: 6 May 2021

Published online: 17 May 2021

\section{References}

1. WHO, IDF. Definition and diagnosis of diabetes mellitus and intermediate hyperglycemia: report of a WHO/IDF consultation. Geneva: WHO, IDF; 2006.

2. Zimmet $P$, Alberti KG, Shaw J. Global and societal implications of the diabetes epidemic. Nature. 2001;414(6865):782-7. https://doi.org/10.103 8/414782a.

3. Hu FB, Manson JE, Stampfer MJ, Colditz G, Liu S, Solomon CG, et al. Diet, lifestyle, and the risk of type 2 diabetes mellitus in women. N Engl J Med. 2001;345(11):790-7. https://doi.org/10.1056/NEJMoa010492.

4. Schmidt MI, Duncan BB, Ishitani L, da Conceicao FG, de Abreu DM, Lana GC, et al. Trends in mortality due to diabetes in Brazil, 1996-2011. Diabetol Metab Syndr. 2015;7(1):109. https://doi.org/10.1186/s13098-015-0105-5.

5. Cho N, Shaw JE, Karuranga S, Huang Y, da Rocha Fernandes JD, Ohlrogge AW, et al. IDF Diabetes Atlas: Global estimates of diabetes prevalence for 2017 and projections for 2045. Diabetes Res Clin Pract. 2018;138:271-81.

6. Nanditha A, Ma RC, Ramachandran A, Snehalatha C, Chan JC, Chia KS, et al. Diabetes in Asia and the Pacific: implications for the global epidemic. Diabetes Care. 2016:39(3):472-85. https://doi.org/10.2337/dc15-1536.

7. Armstrong D. Oxidative stress in applied basic research and clinical practice; 2010.

8. Hu FB. Globalization of diabetes: the role of diet, lifestyle, and genes. Diabetes Care. 2011;34:1249-57.

9. World Diabetes Foundation https://www.worlddiabetesfoundation.org/ projects/afghanistan-wdf15-1206, Assessed 26 Nov. 2019.

10. United Nations Development Program. Human Development Report. http:// hdr.undp.org/en/composite/HDI Assessed 26 Nov. 2019. 
11. Moher D, Liberati A, Tetzlaff J, Altman DG. Preferred reporting items for systematic reviews and meta-analyses: the PRISMA statement. Ann Intern Med. 2009;151(4):264-9. https://doi.org/10.7326/0003-4819-151-4-2009081 80-00135.

12. Saeed KM, Asghar RJ, Sahak MN, Ansari J. Prevalence and risk factors associated with diabetes mellitus among Kabul citizens-Afghanistan, 2012. Int J Diabetes Dev Ctries. 2015;35(3):297-303. https://doi.org/10.1007/s1341 0-014-0270-3.

13. Saeed KM. Prevalence and predictors of diabetes mellitus in Jalalabad City, Afghanistan-2013. 8-1:11)6:2014.

14. Saeed KM. Risk factors and prevalence of diabetes: a cross sectional study in Kabul, Afghanistan 2015. Iran J Diabetes Obes. 2016;8(2):67-76.

15. Saeed KM. Prevalence of diabetes and its risk factors in urban setting of Kandahar City, Afghanistan-2015. IOSR J Pharm. 2016;6(11):53-60.

16. Saeed KM. Prevalence of obesity and some associated factors among adult residents of Mazar-e-Sharif city, Afghanistan. Prevalence. 2016;6(1 1Version): 97-104.

17. Saeed KM. Diabetes mellitus among adults in herat, afghanistan: a crosssectional study. Central Asian J Global health. 2017;6(1). https://doi.org/10.51 95/cajgh.2017.271.

18. von Elm E, Altman DG, Egger M, Pocock SJ, Gøtzsche PC, Vandenbroucke $J \mathrm{P}$, et al. Strengthening the reporting of observational studies in epidemiology (STROBE) statement: guidelines for reporting observational studies. BMJ. 2007;335(7624):806-8. https://doi.org/10.1136/bmj.39335.541 782.AD.

19. R Development Core Team R. A language and environment for statistical computing. Vienna: R Foundation for Statistical Computing; 2008. ISBN 3900051-07-0

20. Barendregt JJ, Doi SA, Lee YY, Norman RE, Vos T. Meta-analysis of prevalence. J Epidemiol Community Health. 2013;67(11):974-8. https://doi. org/10.1136/jech-2013-203104.

21. Cochran GW. The combination of estimates from different experiments. Biometrics. 1954;10(1):101-29. https://doi.org/10.2307/3001666.

22. Higgins JPT, Thompson SG. Quantifying heterogeneity in a meta-analysis. Stat Med 2002;21:1539-1558. doi: https://doi.org/10.1002/sim.1186.

23. Egger M, Davey Smith G, Schneider M, Minder C. Bias in meta-analysis detected by a simple, graphical test. BMJ. 1997;315(7109):629-34. https:// doi.org/10.1136/bmj.315.7109.629.

24. Duval S, Tweedie R. Trim and fill: a simple funnel-plot-based method of testing and adjusting for publication bias in meta-analysis. Biometrics. 2000; 56(2):455-63. https://doi.org/10.1111/j.0006-341X.2000.00455.x.

25. Akhtar S, Nasir JA, Sarwar A, Nasr N, Javed A, Majeed R, et al. Prevalence of diabetes and pre-diabetes in Bangladesh: a systematic review and metaanalysis. BMJ Open. 2020;10(9):e036086. https://doi.org/10.1136/bmjopen-2 019-036086

26. Gyawali B, Sharma R, Neupane D, Mishra SR, van Teijlingen E, Kallestrup P. Prevalence of type 2 diabetes in Nepal: a systematic review and metaanalysis from 2000 to 2014. Glob Health Action. 2015;8(1):29088. https://doi. org/10.3402/gha.v8.29088.

27. Akhtar S, Nasir JA, Abbas T, Sarwar A. Diabetes in Pakistan: a systematic review and meta-analysis. Pak J Med Sci. 2019;35(4):1173-8. https://doi.org/1 0.12669/pjms.35.4.194.

28. Rahman T. The Pashto language and identity-formation in Pakistan. Contemp South Asia. 1995;4(2):151-70. https://doi.org/10.1080/0958493 9508719759.

29. Akhtar S, Khan Z, Rafiq M, Khan A. Prevalence of type II diabetes in district Dir lower in Pakistan. Pakistan J Med Sci. 2016;32(3):622-5. https://doi.org/ 0.12669/pjms.323.9795.

30. Akhtar S, Shah SWA, Javed S, Alina A. Prevalence of diabetes and prediabetes in district swat Pakistan. Pak J Med Sci. 2021;71:243-6. https:// doi.org/10.47391/JPMA.548.

31. American Diabetes Association. Diagnosis and classification of diabetes mellitus. Diabetes Care. 2010;33(Supplement 1):S62-9.

\section{Publisher's Note}

Springer Nature remains neutral with regard to jurisdictional claims in published maps and institutional affiliations.

Ready to submit your research? Choose BMC and benefit from:

- fast, convenient online submission

- thorough peer review by experienced researchers in your field

- rapid publication on acceptance

- support for research data, including large and complex data types

- gold Open Access which fosters wider collaboration and increased citations

- maximum visibility for your research: over $100 \mathrm{M}$ website views per year

At BMC, research is always in progress.

Learn more biomedcentral.com/submissions 